\title{
BMG Global Heath Gender equality and the gender gap in life expectancy in the European Union
}

\author{
Ana-Catarina Pinho-Gomes (D) , , ${ }^{1,2}$ Amy Vassallo (D) , ${ }^{3}$ Cheryl Carcel, ${ }^{3}$ \\ Sanne Peters, ${ }^{1,3,4}$ Mark Woodward ${ }^{1,3}$
}

To cite: Pinho-Gomes A-C, Vassallo A, Carcel C, et al. Gender equality and the gender gap in life expectancy in the European Union. BMJ Global Health 2022;7:e008278. doi:10.1136/ bmjgh-2021-008278

Handling editor Sanni Yaya

- Additional supplemental material is published online only. To view, please visit the journal online (http://dx.doi.org/10. 1136/bmjgh-2021-008278)

Received 13 December 2021 Accepted 20 January 2022

Check for updates

(C) Author(s) (or their employer(s)) 2022. Re-use permitted under CC BY-NC. No commercial re-use. See rights and permissions. Published by BMJ.

${ }^{1}$ The George Institute for Global Health, Imperial College London, London, UK

${ }^{2}$ School of Life Course \& Population Sciences, King's College London, London, UK ${ }^{3}$ The George Institute for Global Health, University of New South Wales, Sydney, New South Wales, Australia

${ }^{4}$ Julius Center for Health Sciences and Primary Care, University Medical Center Utrecht, Utrecht, The Netherlands

Correspondence to

Dr Ana-Catarina Pinho-Gomes; a.pinho-gomes@imperial.ac.uk

\section{ABSTRACT}

Introduction Life expectancy (LE) depends on the wider determinants of health, which have different impact in women and men. Therefore, this study aimed to investigate whether gender equality was correlated with $L E$ in women and men. Methods Gender equality in the 27 European Union (EU) member states between 2010 and 2019 was estimated using a modified Gender Equality Index (mGEI), based on the index developed by the European Institute for Gender Equality. The correlation between this mGEl and LE and the gender gap in LE was calculated using the Spearman correlation coefficient.

Results Between 2010 and 2019, LE increased more for men than women, which resulted in a narrowing of the gender gap in LE in the EU. During the same period, there was an increase in gender equality, as measured by the mGEl, although with substantial heterogeneity between countries. There was a strong correlation between the mGEl and the gender gap in $\operatorname{LE}(-0.880)$, which was explained by a stronger correlation between the $\mathrm{mGEl}$ and longer LE in men than in women $(0.655$ vs 0.629 , respectively). The domains of the mGEl most strongly associated with a narrowing of the gender gap in LE were health, money and knowledge, while power was the domain with the weakest association

Conclusions Gender equality appears to be at least as beneficial to men as women with regard to LE, thus reinforcing the key role gender equality plays in improving population health and longevity.

\section{INTRODUCTION}

Life expectancy (LE) at birth is a well-recognised indicator of the overall health of a population. Although countries in the European Union (EU) share common goals and values and operate in a common economic area, stark inequalities in LE exist. For instance, in 2020, LE ranged from 77.5 years in Bulgaria to 85.3 years in France for women and from 69.9 years in Bulgaria to 80.8 years in Malta for men. ${ }^{1}$ Also, $\mathrm{LE}$ across the EU has increased at a different pace, and the upward trend observed over the last centuries has recently slowed down, or even stalled, in some countries. ${ }^{2}$

Women outlive men globally and in the EU. ${ }^{2}$ Consequently, around $90 \%$ of all known supercentenarians (ie, over 110 years old) worldwide are women. ${ }^{3}$ However, as a result of

\section{Key questions}

What is already known?

- Previous observational studies showed life expectancy is influenced by the wider determinants of health, such as housing and working conditions, money, and education.

- There are stark gender inequalities related to these wider determinants of health, as illustrated, for instance, by women's representation in the workforce, the gender pay gap or the gendered societal roles that place the burden of informal care on women.

\section{What are the new findings?}

- By using a robust and comprehensive index to estimate gender equality across the 27 member states of the European Union, this study demonstrated gender equality is strongly correlated with a narrowing of the gender gap in life expectancy, which is explained by the stronger positive correlation between gender equality and life expectancy for men than women.

- Furthermore, this study suggested gender equality in some domains, such as money, knowledge and health, may be more important for life expectancy than others, such as power.

\section{What do the new findings imply?}

- Gender equality, considered broadly across multiple domains of life, seems to be strongly correlated with longevity, particularly for men.

- This lends further support to evidence currently available showing gender equality benefits women and men alike and contributes to healthier and longer-living populations.

living longer, women spend a greater proportion of their lives in poor health, ${ }^{4}$ a phenomenon known as 'expansion of morbidity'. ${ }^{5}$ The underlying reasons for the persisting gender gap in LE are likely multifactorial, involving biological, behavioural and environmental factors, including social factors. ${ }^{6}$ If biology were the sole cause behind the gender gap in LE, the gap would be relatively constant over time and across societies. However, the gender gap in LE varies considerably by time and context. ${ }^{7}$ 
The wider determinants of health, such as working and living conditions, exposure to pollution, access to healthcare, education, income, and social support, are also inextricably associated with LE. ${ }^{8}$ For instance, those with higher levels of education may be better informed about healthy lifestyles (eg, non-smoking, healthy diet and physical activity), ${ }^{9}$ and those earning higher income may be able to afford healthier food and live and work in environments with lower exposure to risk factors, such as air and noise pollution and cold and damp environments. ${ }^{10}$ Importantly, the wider determinants of health influence women and men differently. For instance, in 2019, 67\% of women across the EU were employed compared with $79 \%$ of men. ${ }^{11}$ Also, women earnt, on average, $14 \%$ less per hour than men and this has changed minimally over the last decade. Therefore, it is possible that the unequal impact of the wider determinants of health on women and men may contribute to the gender gap in LE.

The gendered effects of the COVID-19 pandemic have been well documented at multiple levels, such as work, health and social life. ${ }^{12} 13$ On one hand, the unequal burden usually carried by women in unpaid household work and childcare was exacerbated by the pandemic and global lockdowns. ${ }^{14}$ On the other hand, the economic fallout and job insecurity are lasting longer for women than men. This underpins the concerns that the COVID-19 pandemic may have not only slowed advancement, but also even put the fragile gains in gender equality of the past decades at risk. ${ }^{15}$

Therefore, this study aimed to investigate to what extent gender equality was associated with LE and healthy life expectancy (HLE) in women and men, the gender gap in LE, and the sex difference in excess deaths related to the COVID-19 pandemic in the EU.

\section{METHODS}

\section{Study design}

We conducted an ecological, cross-sectional study to investigate the association between gender equality and LE and the gender gap in LE in the 27 member countries of the EU.

\section{Gender equality}

Gender equality was quantified using the Gender Equality Index (GEI), a publicly available tool developed by the European Institute for Gender Equality to measure the progress of gender equality in the EU. The European Institute for Gender Equality is an autonomous body linked to the European Commission and the European Parliament. ${ }^{16}$ The GEI aims to give visibility to areas that need improvement and to support policy makers to design effective gender equality strategies. In an audit carried out by the European Commission's Joint Research Centre, the GEI was acknowledged as a reliable measurement tool for gender equality in the EU. ${ }^{17}$ It includes six core domains: work, money, knowledge, time, power and health; and two additional domains: violence against women and intersecting inequalities. A detailed description of the GEI and its domains is available in online supplemental table S1. In short, work refers to participation, segregation and quality of work; money relates to financial resources and economic situation; knowledge refers to participation, segregation and attainment in education; time is based on the time spent in care and social activities; power includes the share of leadership positions in political, economic and social institutions; and health covers health status, health-related behaviours and access to healthcare. Each domain is marked between 0 and 100, where 100 represents gender parity, based on the gender gap in each subdomain. The overall GEI is calculated as a weighted average of the scores in each domain and ranges from 0 to 100 , where 100 represents gender parity. The methods underlying the calculation of the GEI are described elsewhere. ${ }^{18}$ The GEI and its domains are available for 2013, 2015, 2017, 2019, 2020 and 2021, using data from 2010, 2012, 2015, 2017, 2018 and 2019, respectively. Although some of the current EU member states joined the EU later than 2010, data from all the current 27 country states are available and were used in this study. As LE and HLE were indicators included in the health domain of the GEI and our goal was to examine how difference in LE relates to gender equity, we recalculated the score for the health domain and the GEI for each country. This modified GEI (mGEI) was used in all analyses.

\section{Life expectancy}

Data on LE and HLE, from 2010 to 2019, for women and men were obtained from the Eurostat website. ${ }^{1}$

\section{Excess deaths related to the COVID-19 pandemic}

Data on excess deaths due to the COVID-19 pandemic, stratified by sex, were obtained from the mortality statistics, publicly available on the Eurostat website. ${ }^{1}$ This indicator is expressed as a percentage of additional deaths in a week (average of 2020-2021) compared with a baseline period (average weekly deaths of 2016-2019). The gender gap in COVID-19-related excess deaths was calculated as the difference in excess deaths between women and men.

\section{Data analysis}

The absolute gender gap in LE or HLE was calculated as the difference in LE and HLE between women and men for each EU member state. Scatter plots with loess smoothing lines were used to display the association between the mGEI, overall and its separate domains, and LE, HLE and the gender gap in LE and HLE. Subgroup analysis was performed for each of the core domains of the mGEI (ie, work, power, knowledge, money, time, health). For the purpose of subgroup analysis, countries were grouped by region as follows:

- Central Europe: France, Germany, the Netherlands, Belgium, Luxembourg, Austria. 

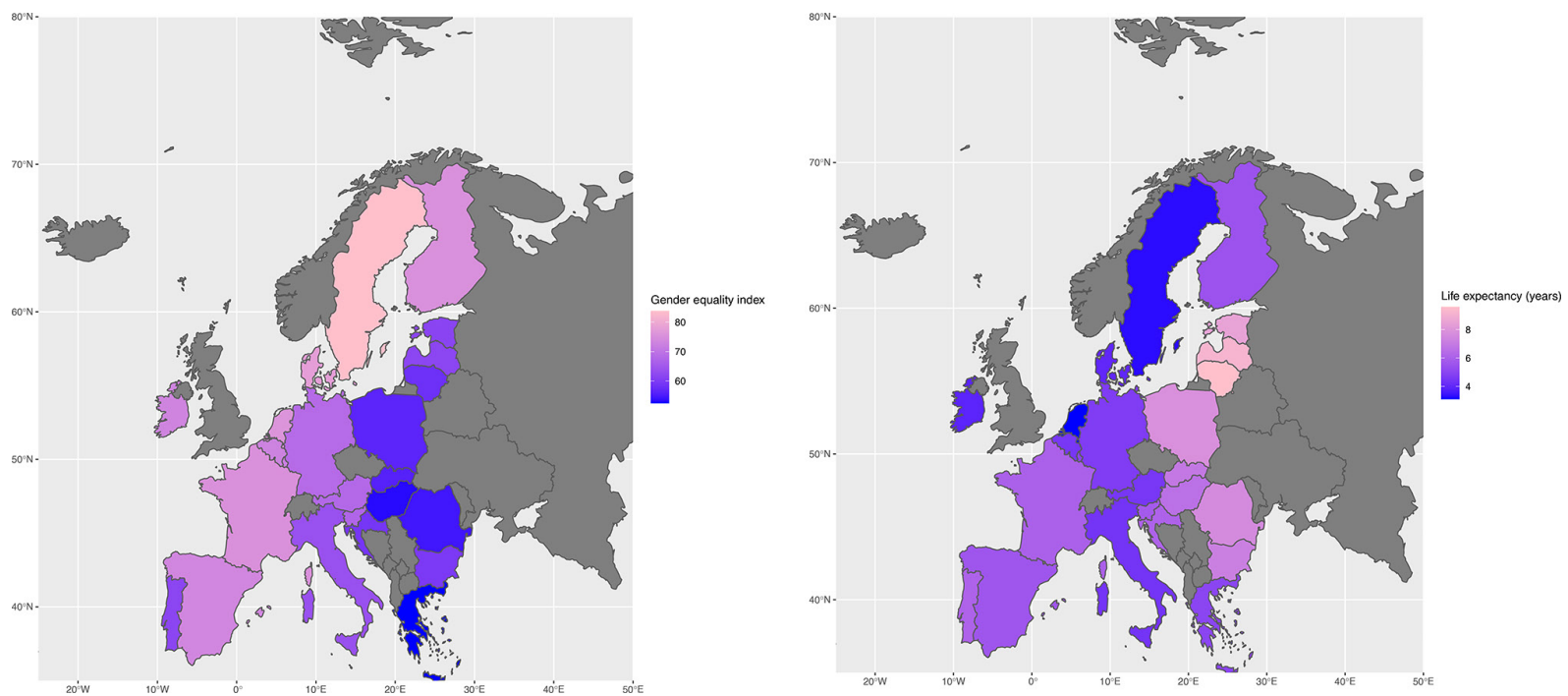

Figure 1 Gender Equality Index and life expectancy gap between women and men in the European Union (EU) member states in 2019. The left panel displays the Gender Equality Index (0-100) in 2019 for all EU member states. The right panel displays the gap in life expectancy between women and men in 2019 for all EU member states. The blue countries have shorter life expectancy gap, while the pink countries have larger life expectancy gap.

- Eastern Europe: Latvia, Lithuania, Estonia, Poland, Romania, Bulgaria, Slovakia, Czechia, Hungary.

- Southern Europe: Portugal, Spain, Italy, Malta, Cyprus, Slovenia, Croatia, Greece.

- Northern Europe: Denmark, Finland, Sweden, Ireland.

Spearman correlation coefficients were computed to estimate the correlation between the mGEI and LE, HLE, gender gap in LE and HLE, and gender gap in COVID19-related excess deaths in the EU overall in 2019. All analyses were carried out using R V.3.6.3.

\section{Patient and public involvement}

Patients and the public were not involved in this study.

\section{RESULTS}

\section{Gender equality}

In 2019, the overall mGEI in the EU was 68. However, there was a large variation between countries, from the lowest of 52.4 in Greece to the highest of 83.8 in Sweden (figure 1, left panel, and online supplemental table S3). There has been a steady increase in the mGEI in the EU since 2010, when it was 63 (figure 2), but with discrepant trends over time between member states (online supplemental figure S1). The largest increase in gender equality over the past decade occurred in Italy and Austria, where the mGEI increased from 53 to 64 and from 58 to 68, respectively. Despite the overall improvement in the mGEI in the EU, this was driven mainly by an increase in gender equality in the domains of power (13.1 points), money (3.3 points) and knowledge (2.9 points). Progress in other domains, such as work (1.9 points) and health (1.2 points), was minimal, and there was a decrease in gender equality in the domain of time ( -0.3 points) (online supplemental table S4).

\section{LE and HLE}

In 2019, LE in the EU was 84.0 years for women and 78.5 years for men (online supplemental table S2). LE ranged from 78.8 years in Bulgaria to 86.7 years in Spain for women and from 70.9 years in Latvia to 81.5 years in Sweden for men in 2019. LE in 2010 was 83.1 years for women and 77 years for men. Therefore, between 2010 and 2019, the gender gap declined from 6.1 years to 5.5 years in the EU overall (figure 2). There were, though, marked differences between countries, from the lowest of 3.1 years in the Netherlands to the highest of 8.5 years in Estonia in 2019 (figure 1, right panel). There were also differences in time trends in the gender gap in LE, with the gap widening in some countries

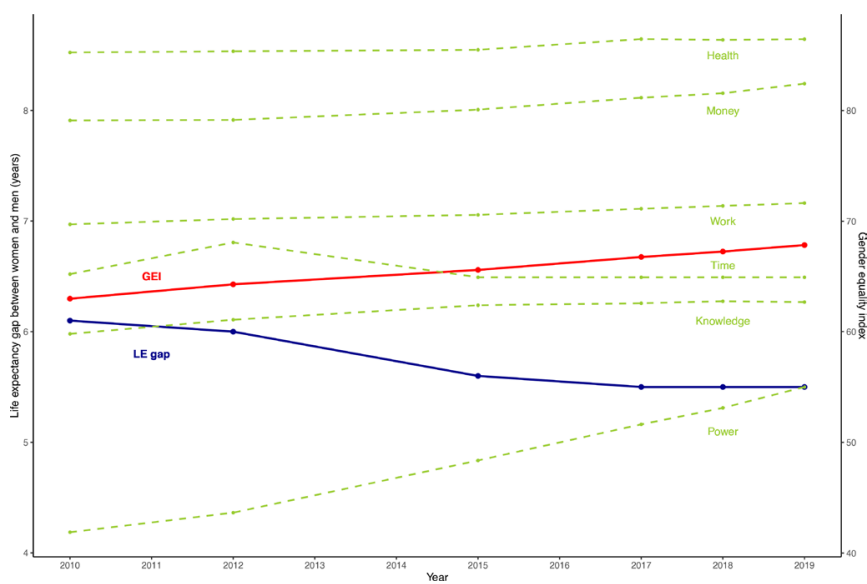

Figure 2 Trends in the Gender Equality Index (GEI) and its domains and life expectancy (LE) gap between women and men in the European Union (EU) from 2010 to 2019. The figure displays the evolution in GEl (red line) and its six core domains (green lines) as well as the change in the LE gap between women and men (blue line) between 2010 and 2019 in the EU. 

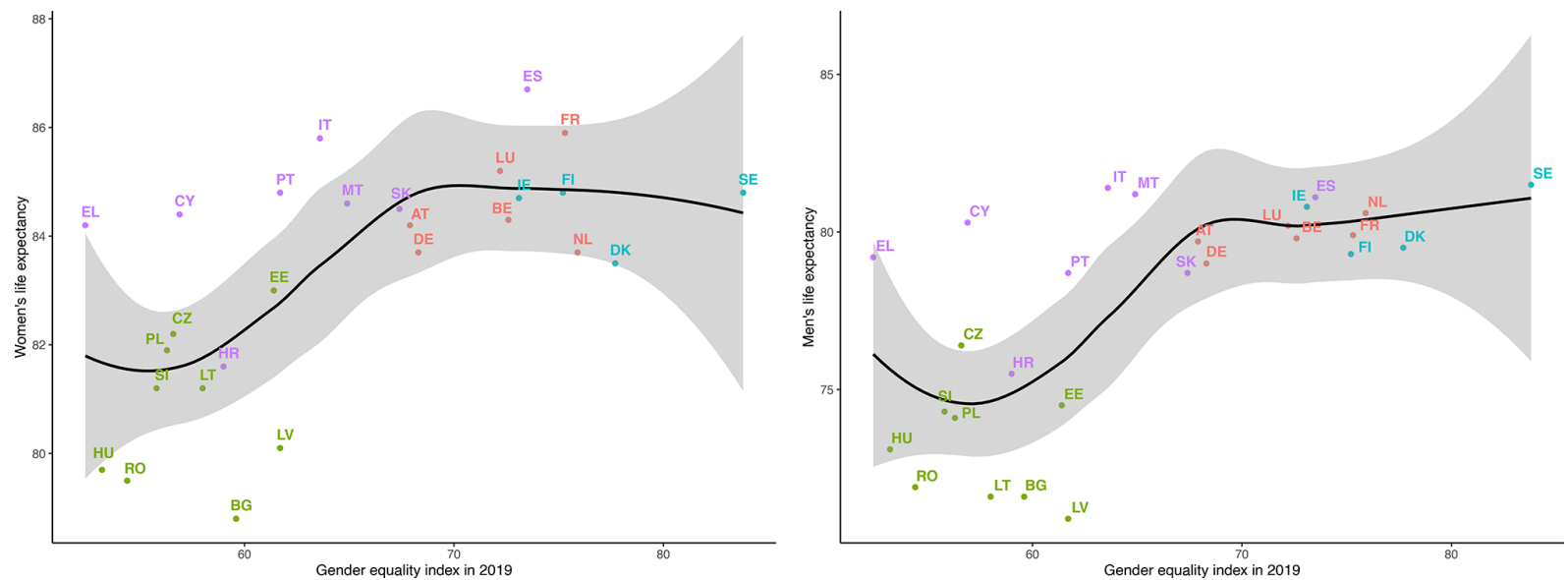

Figure 3 Correlation between Gender Equality Index and life expectancy for women and men in the European Union member states in 2019. Green: Eastern Europe; blue: Northern Europe; pink: Western Europe; purple: Southern Europe. AT, Austria; BE, Belgium; BG, Bulgaria; CY, Cyprus; CZ, Czechia; DK, Denmark; DE, Germany; EE, Estonia; EL, Greece; ES, Spain; FI, Finland; FR, France; HR, Croatia; HU, Hungary; IE, Ireland; IT, Italy; LT, Lithuania; LU, Luxembourg; LV, Latvia; MT, Malta; NL, the Netherlands; PL, Poland; PT, Portugal; RO, Romania; SE, Sweden; SI, Slovakia; SK, Slovenia.

by about 4 years (eg, Estonia and Lithuania) and narrowing by almost 5 years in others (eg, Italy and Denmark) (online supplemental figure S2).

Between 2010 and 2019, HLE increased from 62.2 to 65.1 years for women and from 61.3 to 64.2 years for men in the EU overall (online supplemental table S3), which meant the gender gap in HLE remained stable at 0.9 years. In 2019, HLE ranged from 54.1 years in Ireland to 73.5 years in Luxembourg for women and from 52.2 years in Ireland to 73.8 years in Sweden for men. The gender gap in HLE also varied largely between countries, from as low as -3.1 years (ie, men live a further 3.1 years in full health compared with women) in the Netherlands to 4 years in Bulgaria (ie, women live a further 4 years in full health in comparison with men) (online supplemental table S3 and figure S4).

\section{Correlation between gender equality, LE and HLE}

There was a moderate positive correlation between the mGEI and total LE (Spearman correlation coefficient 0.654 , $\mathrm{p}<0.001$ ) (online supplemental figure S3 and table S5), but no correlation with total HLE (Spearman correlation coefficient 0.228, $\mathrm{p}=0.253$ ) (online supplemental figure $\mathrm{S} 5$ and table S5). There was a stronger correlation between the mGEI and LE in men than in women (figure 3). The mGEI was not significantly correlated with HLE in women or in men (online supplemental figure S4).

Overall, there was a strong negative correlation between the mGEI and the gender gap in LE (Spearman correlation coefficient $-0.880, \mathrm{p}<0.001$ ) (figure 4 and online supplemental table S5). There was a moderate negative correlation between the mGEI and the gender gap in HLE (Spearman correlation coefficient -0.452 , $\mathrm{p}=0.018$ ) (online supplemental figure S6). The domains of the mGEI most strongly correlated with a narrowing of the gender gap in LE were health (Spearman correlation coefficient $-0.880, \mathrm{p}<0.001$ ), money (Spearman correlation coefficient $-0.759, \mathrm{p}<0.001)$ and knowledge
(Spearman correlation coefficient -0.603, p<0.001) (online supplemental figure S7 and table S6). Power was the domain with the weakest correlation with a reduction in the gender gap in LE (Spearman correlation coefficient $-0.387, \mathrm{p}<0.046)$.

\section{Correlation between mGEI and COVID-19 excess deaths}

Overall, there was a weak negative correlation between the GEI and excess deaths due to COVID-19 (Spearman correlation coefficient $-0.261, \mathrm{p}=0.197$ ) (figure 5).

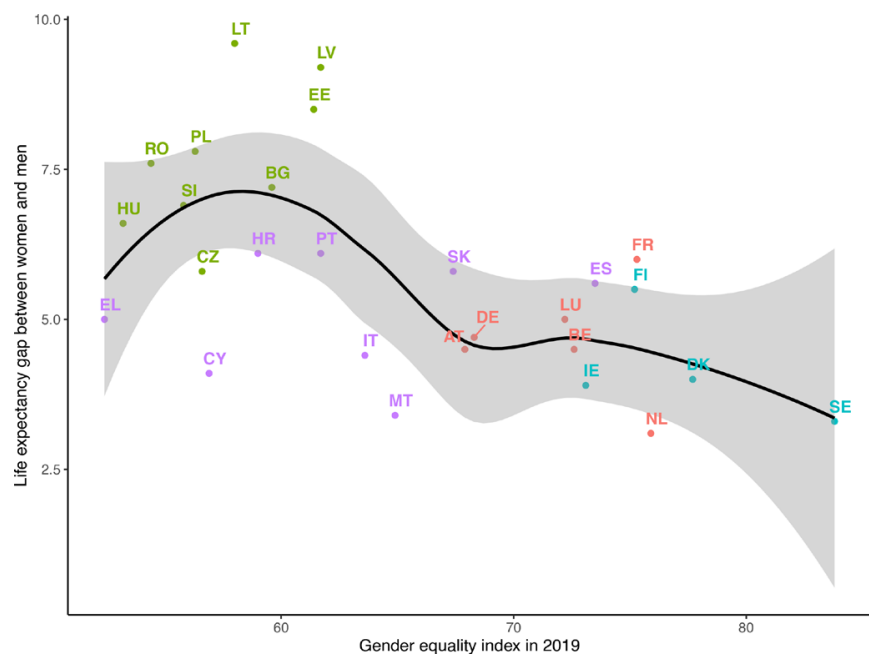

Figure 4 Correlation between the Gender Equality Index and life expectancy gap between women and men in the European Union member states in 2019. Green: Eastern Europe; blue: Northern Europe; pink: Western Europe; purple: Southern Europe. AT, Austria; BE, Belgium; BG, Bulgaria; CY, Cyprus; CZ, Czechia; DK, Denmark; DE, Germany; EE, Estonia; EL, Greece; ES, Spain; FI, Finland; FR, France; HR, Croatia; HU, Hungary; IE, Ireland; IT, Italy; LT, Lithuania; LU, Luxembourg; LV, Latvia; MT, Malta; NL, the Netherlands; PL, Poland; PT, Portugal; RO, Romania; SE, Sweden; SI, Slovakia; SK, Slovenia. 


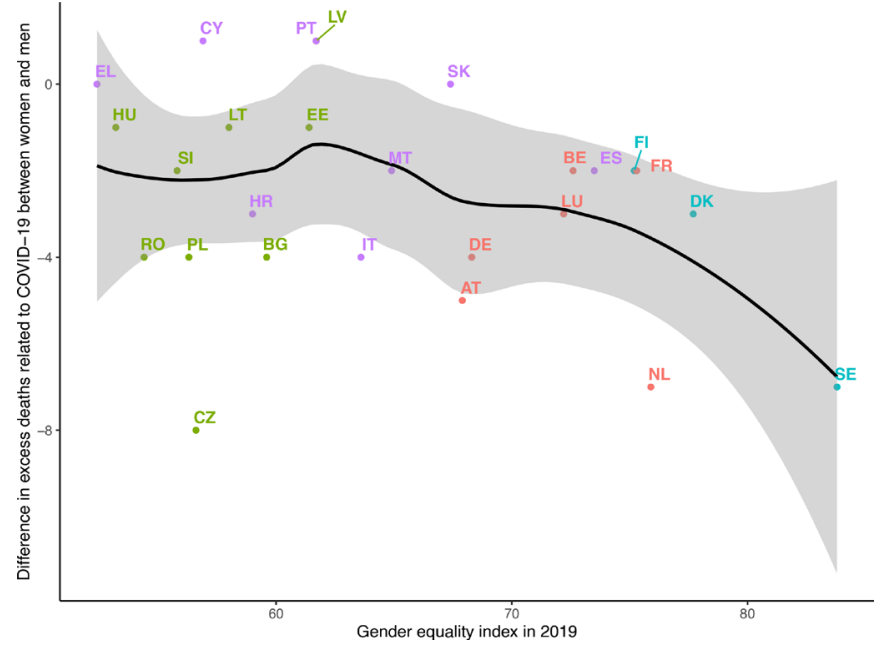

Figure 5 Correlation between the Gender Equality Index and difference in excess deaths related to COVID-19 between women and men in the European Union member states. COVID-19 excess deaths were calculated as the excess weekly deaths in 2020-2021 in comparison with average weekly deaths for 2016-2019. Green: Eastern Europe; blue: Northern Europe; pink: Western Europe; purple: Southern Europe. AT, Austria; BE, Belgium; BG, Bulgaria; CY, Cyprus; CZ, Czechia; DK, Denmark; DE, Germany; EE, Estonia; EL, Greece; ES, Spain; FI, Finland; FR, France; HR, Croatia; HU, Hungary; IT, Italy; LT, Lithuania; LU, Luxembourg; LV, Latvia; MT, Malta; NL, the Netherlands; PL, Poland; PT, Portugal; RO, Romania; SE, Sweden; SI, Slovakia; SK, Slovenia.

\section{DISCUSSION}

Overall, LE increased in the EU between 2010 and 2019, but the increase was more marked for men than women, which resulted in a narrowing of the gender gap in LE. During the same period, there was an increase in gender equality, as measured by the mGEI, although with substantial heterogeneity between the 27 member states. Gender equality also evolved differently across the six core domains of the mGEI. While there was a large increase in power of 13 points, improvements in other domains, such as health, work and money, were small and there was even a decline in gender equality in time. Overall, countries with greater gender equality had a narrower gender gap in LE and HLE. The correlation between the mGEI was stronger for LE than HLE. The smaller LE gap in more gender-equal countries was explained by the stronger correlation between the mGEI and longer LE in men than in women. The domains most strongly associated with a narrowing of the gender gap in LE were health, money and knowledge, while power was the domain with the weakest association.

Despite the general improvement in gender equality in the EU over the past decade, there are marked differences in progress between countries and domains of the mGEI. Indeed, the 4.9-point increase in the mGEI between 2010 and 2019 resulted mainly from an improvement in gender equality in power, which is the domain with the weakest association with the gender gap in LE. This improvement in gender equality in power has largely resulted from gender quotas, which have been widely adopted by political systems to encourage women's participation. ${ }^{19}$ However, this apparent increase in women's representation in political systems may not translate into actual policies promoting gender equality or their implementation. ${ }^{20}$ This is because poorly implemented gender quotas can be tokenistic as women continue to experience substantial barriers to achieving senior leadership positions, which leads to women occupying positions that hold little or no power to influence decision making. In addition, a time lag is expected from greater women leadership, translating into noticeable improvements in gender equality in other domains of life. This may partially underpin the weak association between power and LE. Therefore, although quotas are an important mechanism to foster women's representation in multiple fields, such as politics, science and academia or sports, they need to guarantee women are proportionally represented at senior level. Otherwise, gender quotas may not truly result in a fair share of power between women and men. Furthermore, it is important gender quotas translate into fair remuneration as there is ample evidence women continue to be paid less for equivalent jobs. ${ }^{21}$ Ironically, money is, after health, the mGEI domain with the strongest association with a narrowing of the gender gap in LE, thus suggesting financial gender parity may be particularly beneficial for men's longevity.

Although overall LE increased in all EU member states over the last decade, the increase was more marked in men than in women, thus resulting in a narrowing of the gender gap in LE. This increase in LE and reduction in the gender gap in LE were strongly correlated with an increase in gender equality across several domains, including money, work and knowledge. This strong association is not unexpected considering that LE broadly mirrors population health, which depends on the wider determinants of health, such as working and living housing conditions, pollution, and education. $^{22} 23$ On the other hand, some may argue the observed correlation is explained by economic development, which has been shown to result in longer LE. ${ }^{24}$ However, some of the countries with the highest mGEI, such as Spain, the Netherlands, Finland and Sweden, are less economically prosperous (according to the widely used metric of gross domestic product) than countries with lower mGEI, such as Germany. ${ }^{25}$ This suggests that the observed correlation is not fully explained by economic development, and hence gender equality may have benefits itself for population longevity.

In addition, the association between the mGEI and LE was stronger for men than women, suggesting that gender equality appears to be more advantageous to men than women. Therefore, the association between the mGEI and narrowing of the gender gap in LE is explained by a larger increase in men's LE than women's LE, rather than a decline in women's LE. This demonstrates men have at least as much to gain from gender 
equality as women, thus supporting the wider benefits of gender equality for society as a whole.

There are several potential explanations for the observed correlation between gender equality and the narrowing of the gender gap in LE. First, neonatal, infant and childhood mortality rates are higher in boys than in girls. ${ }^{26}$ Gender equality, and by extension better health for women, can lower mortality in the first years of life, thus increasing longevity to a greater extent among boys than girls. Second, in countries with more gender-equal societies, women may be increasingly adopting healthdamaging lifestyles that were traditionally more prevalent among men, such as smoking and drinking. ${ }^{27}$ This could have slowed down improvement in women's LE, thus ultimately reducing the gender gap. Third, gender equality in the labour market allows more women to enter the workforce and take up risk-prone jobs that were previously only accessible to men. ${ }^{28}{ }^{29}$ This could stifle the expansion of women's LE, thus narrowing the gender gap. Fourth, it is possible that gender equality results in more women working as health professionals, and health outcomes seem to be better for patients looked after by doctors who are women than men. ${ }^{30}$ As men have a higher rate of preventable premature mortality, they are more likely than women to benefit from healthcare provided by doctors who are women, in countries with greater gender equality.

Although the mGEI was only weakly correlated with excess deaths related to COVID-19, evidence has been accruing on the profound impact of COVID-19 on women and, particularly, on gender equality. ${ }^{31}$ Even if the risk of severe disease and death due to COVID-19 was higher for men than women, the multipronged impact of the pandemic on women's lives cannot be overlooked. ${ }^{32}$ Women bore the brunt of childcare and household responsibilities, especially during lockdowns, with dire consequences on their careers and income. ${ }^{1232}$ For instance, women in France, Germany and Spain will have an increased need for pandemic-induced job transitions at rates four times higher than men. ${ }^{33}$ In addition, women in emerging economies seem to be the worst affected by the pandemic, with about $80 \%$ reporting poor mental and physical health, increased workload, job insecurity, and lack of safe and healthy workplaces. ${ }^{34}$ Considering the correlation between the different domains of the mGEI, particularly money and work and longevity, gender equality must be at the fore of recovery plans not only in Europe but worldwide to ensure women's disadvantage during the pandemic is not perpetuated and magnified in its aftermath.

Gender equality remains far from a reality even among the high-income and developed 27 EU member states. Progress over the past decade has been slow and the European Institute for Gender Equality estimated it will take nearly three generations to achieve gender equality across multiple domains in the EU at the current pace, especially because the gendered consequences of COVID-19 may have slowed down progress even further. ${ }^{16}$ This study showed gender equality is not just a question of gender justice and fairness for women, but it might also extend population longevity, with men benefiting even more in terms of LE than women. Therefore, it is crucial governments of EU member states and, by extension, countries across the globe implement policies that promote gender equality across all domains of the mGEI, such as work and money, knowledge and education, and power. Greater gender equality may not only contribute to a healthier and longer-living society but also lead to economic prosperity. Indeed, an economic modelling study (including 46 countries from all continents) compared a scenario in which no action was taken to address the gender gap at work (ie, do-nothing scenario) with a scenario that assumed all countries matched the progress towards gender parity of the fastest-improving country in their region. ${ }^{35}$ It was estimated $\$ 13$ trillion could be added to global gross domestic product if best-in-region genderparity improvements were achieved by 2030 . This scenario would raise the female to male labour force participation ratio from 0.61 in 2020 to 0.71 in 2030, with the creation of 230 million new jobs for women globally compared with the do-nothing scenario by 2030. Therefore, there are compelling economic benefits to take prompt action to address the gender gap in work, which is a key driver of women's emancipation and empowerment. ${ }^{36}$

\section{Limitations}

There are some limitations to acknowledge in this study. First, ecological bias is possible as it is uncertain whether correlations at country level reflect associations at individual level. Second, the observed correlation between gender equality and longevity may not be causal. Third, data were only analysed for EU member states and it is unclear whether findings are generalisable to other countries across the globe. The United Nations has also developed a GEI, but it is based on a narrow range of indicators due to lack of reliable data for many countries worldwide. Fourth, the binary definition of gender adopted by this study does not reflect the gender diversity of the population. ${ }^{37}$ There is heterogeneity within the groups of women and men, which may be partially explained by the intersection with other drivers of inequalities, such as ethnicity and social class. ${ }^{38}$

\section{CONCLUSIONS}

There is a strong correlation between gender equality and the gender gap in LE, which is explained by the stronger correlation between gender equality and LE for men than women. Therefore, gender equality seems to be at least as beneficial to men as to women, thus reinforcing the importance of making gender equality a priority for the improvement of population health and longevity.

Twitter Ana-Catarina Pinho-Gomes @ana_cat_pg and Amy Vassallo @amyjvassallo

Contributors ACPG, SP and MW designed this study. ACPG extracted and analysed the data and drafted the manuscript. All authors reviewed the manuscript. ACPG is the guarantoor and accepts full responsibility for the work and the conduct of the study, had access to the data, and controlled the decision to publish.

Funding MW is supported by the National Health and Medical Research Council of Australia (grants APP1149987 and APP1174120). CC is funded by the National 
Heart Foundation of Australia (Postdoctoral Fellowship 102741). A-CP-G is funded by an Academic Clinical Fellowship by the National Institute for Health Research. SP is supported by a UK Medical Research Council Skills Development Fellowship (MR/P014550/1)

Map disclaimer The inclusion of any map (including the depiction of any boundaries therein), or of any geographic or locational reference, does not imply the expression of any opinion whatsoever on the part of BMJ concerning the legal status of any country, territory, jurisdiction or area or of its authorities. Any such expression remains solely that of the relevant source and is not endorsed by BMJ. Maps are provided without any warranty of any kind, either express or implied.

Competing interests MW is a consultant for Amgen, Kyowa Kirin and Freeline.

Patient consent for publication Not required.

Ethics approval This study does not involve human participants.

Provenance and peer review Not commissioned; externally peer reviewed.

Data availability statement All data relevant to the study are included in the article or uploaded as supplemental information.

Supplemental material This content has been supplied by the author(s). It has not been vetted by BMJ Publishing Group Limited (BMJ) and may not have been peer-reviewed. Any opinions or recommendations discussed are solely those of the author(s) and are not endorsed by BMJ. BMJ disclaims all liability and responsibility arising from any reliance placed on the content. Where the content includes any translated material, BMJ does not warrant the accuracy and reliability of the translations (including but not limited to local regulations, clinical guidelines, terminology, drug names and drug dosages), and is not responsible for any error and/or omissions arising from translation and adaptation or otherwise.

Open access This is an open access article distributed in accordance with the Creative Commons Attribution Non Commercial (CC BY-NC 4.0) license, which permits others to distribute, remix, adapt, build upon this work non-commercially, and license their derivative works on different terms, provided the original work is properly cited, appropriate credit is given, any changes made indicated, and the use is non-commercial. See: http://creativecommons.org/licenses/by-nc/4.0/.

\section{ORCID iDs}

Ana-Catarina Pinho-Gomes http://orcid.org/0000-0001-9895-1493

Amy Vassallo http://orcid.org/0000-0002-8473-7549

\section{REFERENCES}

1 Eurostat. Mortality and life expectancy statistics. Available: https:// ec.europa.eu/eurostat/statistics-explained/index.php?title=Mortality and_life_expectancy_statistics [Accessed 19 Nov 2021].

2 GBD 2019 Demographics Collaborators. Global age-sexspecific fertility, mortality, healthy life expectancy (HALE), and population estimates in 204 countries and territories, 1950-2019: a comprehensive demographic analysis for the global burden of disease study 2019. Lancet 2020;396:1160-203.

3 Austad SN, Fischer KE. Sex differences in lifespan. Cell Metab 2016;23:1022-33.

4 Luy M, Minagawa Y. Gender gaps--Life expectancy and proportion of life in poor health. Health Rep 2014;25:12-19.

5 Kingston A, Robinson L, Booth $\mathrm{H}$, et al. Projections of multimorbidity in the older population in England to 2035: estimates from the population ageing and care simulation (PACSim) model. Age Ageing 2018;47:374-80.

6 Allel K, Salustri F, Haghparast-Bidgoli H, et al. The contributions of public health policies and healthcare quality to gender gap and country differences in life expectancy in the UK. Popul Health Metr 2021;19:40.

7 Govindaraju D, Atzmon G, Barzilai N. Genetics, lifestyle and longevity: lessons from centenarians. Appl Trans/ Genom 2015;4:23-32.

8 Mackenbach JP, Valverde JR, Bopp M, et al. Determinants of inequalities in life expectancy: an international comparative study of eight risk factors. Lancet Public Health 2019;4:e529-37.

9 Mackenbach JP, Stirbu I, Roskam A-JR, et al. Socioeconomic inequalities in health in 22 European countries. $N$ Engl J Med 2008;358:2468-81.

10 Gibson M, Petticrew M, Bambra C, et al. Housing and health inequalities: a synthesis of systematic reviews of interventions aimed at different pathways linking housing and health. Health Place 2011;17:175-84.
11 European Comission. The gender pay gap situation in the EU. Available: https://ec.europa.eu/info/policies/justice-andfundamental-rights/gender-equality/equal-pay/gender-pay-gapsituation-eu en [Accessed 12 Nov 2021].

12 King MM, Frederickson ME. The pandemic penalty: the gendered effects of COVID-19 on scientific productivity. Socius 2021;7:237802312110069.

13 Pinho-Gomes A-C, Peters S, Thompson K, et al. Where are the women? Gender inequalities in COVID-19 research authorship. BMJ Glob Health 2020;5.

14 Gewin V. The career cost of COVID-19 to female researchers, and how science should respond. Nature 2020;583:867-9.

15 United Nations Conference on Trade and Development. COVID-19 threatens four 'lost decades' for gender equality: UNCTAD, 2021. Available: https://unctad.org/news/covid-19-threatens-four-lostdecades-gender-equality [Accessed 28 Nov 2021].

16 European Institute for Gender Equality. Gender equality index. Available: https://eige.europa.eu/gender-equality-index/about [Accessed 19 Nov 2021].

17 Papadimitriou E, Norlen H, Del Sorbo M. JRC statistical audit of the 2020 gender equality index. publications office of the European Union, 2020. Available: https://publications.jrc.ec.europa.eu/ repository/handle/JRC122232 [Accessed 28 Nov 2021]

18 Barbieri D, Karu M, Lestón IR. Gender equality index 2017: methodological report. Luxembourg: European Institute for Gender Equality, 2017.

19 Cruz C, Rivera B. Measuring the impact of gender Quotas on political institutions, 2021. Available: https://blogs.iadb.org/ideasmatter/en/measuring-the-impact-of-gender-quotas-on-politicalinstitutions/ [Accessed 23 Nov 2021].

20 Clayton A. How do electoral gender Quotas affect policy? Annual Review of Political Science 2021;24:235-52.

21 Elsesser K. On equal pay day, what is the real gender pay gap? Forbes, 2020. Available: https://www.forbes.com/sites/kimelsesser/ 2020/03/30/on-equal-pay-day-what-is-the-real-gender-pay-gap/? sh=7ce1e4f528ba [Accessed 23 Nov 2021].

22 Li Y, Pan A, Wang DD, et al. Impact of healthy lifestyle factors on life Expectancies in the US population. Circulation 2018;138:345-55.

23 Mondal MNI, Shitan M. Relative importance of demographic, socioeconomic and health factors on life expectancy in low- and lower-middle-income countries. J Epidemiol 2014;24:117-24.

24 Miladinov G. Socioeconomic development and life expectancy relationship: evidence from the EU accession candidate countries. Genus 2020;76:2.

25 Eurosta. Real GDP per capita, 2020. Available: https://ec.europa.eu/ eurostat/web/products-datasets/-/sdg_08_10 [Accessed 28 Nov 2021]

26 Di Renzo GC, Rosati A, Sarti RD, et al. Does fetal sex affect pregnancy outcome? Gend Med 2007;4:19-30.

27 Feeny E, Dain K, Varghese C, et al. Protecting women and girls from tobacco and alcohol promotion. BMJ 2021;374:n1516.

28 European Commission. Women's situation in the labour market. Available: https://ec.europa.eu/info/policies/justice-and-fundamentalrights/gender-equality/women-labour-market-work-life-balance/ womens-situation-labour-market_en [Accessed 22 Nov 2021].

29 Madgavkar A, Manyika J, Krishnan M. The future of women at work: transitions in the age of automation. McKinsey Global Institute, 2019.

30 Tsugawa Y, Jena AB, Figueroa JF, et al. Comparison of hospital mortality and readmission rates for Medicare patients treated by male vs female physicians. JAMA Intern Med 2017;177:206-13.

31 Azcona G, Bhatt A, Encarnacion J. From insight to action: gender equality in the wake of COVID-19: UN Women 2020.

32 Burns T, Huang J, Krivkovich A. Women in the workplace. McKinsey Global Institute, 2021

33 Lund S, Madgavkar A, Manyika J. The future of work after COVID-19. McKinsey Global Institute, 2021.

34 Ellingrud K, Krishnan M, Krivkovich A. Diverse employees are struggling the most during COVID-19-here's how companies can respond. McKinsey Global Institute, 2020.

35 Madgavkar A, White O, Krishnan M. COVID-19 and gender equality: Countering the regressive effects. McKinsey Global Institute, 2020.

36 Runde DF, Ramanujam SR. Empowering women through skills and workforce development. centre for strategic and international studies, 2020. Available: https://www.csis.org/analysis/empowering-womenthrough-skills-and-workforce-development [Accessed 14 Jan 2022].

37 Weber AM, Gupta R, Abdalla S, et al. Gender-related data missingness, imbalance and bias in global health surveys. BMJ Glob Health 2021;6:e007405.

38 Wilchins R. Gender norms and intersectionality: connecting race, class and gender. Rowman \& Littlefield, 2019. 